\title{
DA CARTOGRAFIA À COREMÁTICA: representações espaciais para uma espacialidade mutante
}

\author{
Msc. Oséias da Silva Martinuci \\ Doutorando em Geografia pela UNESP Presidente Prudente \\ Jd. Santa Helena, Rua Roberto Simonsen, 305, CEP: 19060-900 Presidente Prudente (SP), Brasil \\ Tel: (55 41) 3229.5388 - ramal 5456 - oseiasmartinuci@yahoo.com.br
}

\begin{abstract}
RESUMO
No presente artigo, discuto a importância da cartografia para o conhecimento geográfico, ao mesmo tempo em que exponho a necessidade de se relativizarem as formas rígidas de representação espacial. A complexidade e a complexificação que se operam hoje sobre o território imprimem novas configurações e dinâmicas espaciais, para as quais o geógrafo precisa encontrar formas apropriadas de representação. As dinâmicas sociais não estão submetidas a formas rígidas, assim como as configurações socioespaciais a elas associadas. Consequentemente, as representações precisam expressar de maneira mais adequada essa realidade. Muitas vezes, as cartografias que se fazem mostram-se inaptas para tal tarefa, levando os pesquisadores, especialmente o geógrafo, a refletir tanto sobre a forma de pensar o fenômeno quanto sobre a maneira de expressá-lo.
\end{abstract}

Palavras-chave: Geografia, cartografia, teoria dos coremas

\begin{abstract}
In this paper, by exposing the need to make less rigid the forms of spatial representation, I discuss the importance of cartography for the geographical knowledge. The complexity existing today in the territory creates new spatial configurations and dynamics. For this complexity, the geographer needs to find appropriate forms of representation. Nor the social dynamics neither the associated socio-spatial configurations are submitted to rigid forms. Consequently, the representations need to express this reality in a more adequate way, but many times the cartographies are made in unable ways for achieving that.
\end{abstract}

Key words: Geography, cartography, theory of chorems.

\section{RÉSUMÉ}

Dans cet article, je discute l'importance de la cartographie pour la connaissance géographique au même temps où j'expose la nécessité de relativiser les formes rigides de représentation spatiale. La complexité et la complexification qui ont lieu sur le territoire aujourd'hui créent des nouvelles configurations et dynamiques spatiales pour lesquelles le géographe a besoin de trouver des formes appropriées de représentation. Tant les dynamiques sociales que les configurations socio-spatiales associées ne sont pas soumises à des formes rigides. Par conséquent, il faut que les représentations expriment de façon plus adéquate cette réalité. Plusieurs fois les cartographies faites se montrent inaptes pour tel but et amènent les chercheurs, spécialement le géographe, à réfléchir sur la manière de penser le phénomène et sur la façon de l'exprimer.

Mots-clés: Géographie, cartographie, théorie des chorèmes.

\section{INTRODUÇÃO}

Apesar dos grandes avanços operados no campo de uma cartografia técnica e tecnológica, portanto, mais aplicada, o desenvolvimento da cartografia enquanto ciência é um evento relativamente novo e data do Pós-Segunda Guerra Mundial, como nos esclarece Kanabuco (1995). Para ele, isso se deve ao fato de que durante muito tempo os levantamentos cartográficos estavam ligados ao exército, o que evidenciava uma preocupação mais estratégica que à científica, caracterizada pela priorização dos aspectos técnicos e práticos.

Até então pouca importância era dada à cartografia temática e seus princípios fundamentais (BOARD, 1994). Levando em consideração essa problemática que se impunha no pós-guerra, cartógrafos e geógrafos do mundo inteiro se reúnem em torno da ACI (Associação Cartográfica Internacional, fundada em 1959) e passam a se preocupar com os problemas teóricos da cartografia. Dentre os mais importantes, poderíamos citar aqui alguns, como T. Kanabuko (1995), C. Koeman 
(1995), C. Board (1994) e A. Kolacny (1992). Mesmo existindo divergências teóricas entre esses pensadores da cartografia, havia uma problemática central: dar estatuto de ciência à cartografia, considerando o processo de produção e uso de mapas. Kolacny (1992), em especial, defendeu a valorização do usuário do mapa, sob o que ficou conhecido como "teoria da informação cartográfica”. É, principalmente, com Kolacny que se passa a pensar o processo cartográfico. Para Koeman "um mapa deve dar prazer aos olhos, portanto, ele estimula o interesse e seu conteúdo é melhor assimilado pelos usuários" (1995, p. 10). A afirmação desse autor retrata bem a preocupação dos cartógrafos e geógrafos reunidos em torno da ACI, na busca pelo desenvolvimento de uma ampla teoria da comunicação cartográfica. Comunicar eficientemente as informações contidas nos mapas era um ponto a se avançar. No entanto, havia grandes dificuldades, a começar pela não existência de convenções cartográficas, ou mais precisamente uma linguagem cartográfica, dada pela grande amplitude de sociedades de cartografia e de geografia. Reuní-las era uma das preocupações centrais, evidenciada nas palavras de Kolacny quando afirmava que a cartografia só alçaria avanços significativos quando houvesse um grande processo de cooperação entre geógrafos e cartógrafos do mundo inteiro.

Somente no final da década de 1960 é que o impasse referente às convenções cartográficas, em especial, à linguagem cartográfica é, em parte, resolvido com a publicação da obra de Jacques Bertin, "Semiologie graphique", considerada uma das mais importantes contribuições para a cartografia desde há muito tempo. É bem possível que, dadas as necessidades da Geografia em formular hipóteses, reconhecer processos, estabelecer padrões, culmina na década de 80, também na França, a sistematização da teoria da modelização gráfica, feita por Roger Brunet. Isso, de certa forma, vai ao encontro dos anseios de Board (1995), para o qual a transmissão de fatos e processos geográficos de forma inteligível deve ser buscada até mesmo em detrimento do detalhe e da precisão.

Mais recentemente, com o intenso avanço da tecnologia e da informação, a dimensão espacial, como estratégia de ação, fica mais clara com o uso de satélites que capturam em detalhes objetos da superfície terrestre. Além disto, os impactos da linguagem computacional sobre a cartografia foram marcantes (MARTINELLI, 2006; JOLY, 2007; LOCH, 2006; ROSA, 1996), exigindo, inclusive, novas discussões e revisão de conceitos que a definiam. Vários pacotes tecnológicos têm sido desenvolvidos como uma demanda nascida da valorização da dimensão espacial como estratégia da ação, tanto para a pesquisa quanto para o mercado. É comum, atualmente, a constatação de que várias empresas estão adotando pacotes de geoprocessamento, por exemplo, para a ampliação de seus lucros. Concomitante a isso também se dá a popularização do acesso a esses pacotes tecnológicos, o que exige novas abordagens sobre o processo cartográfico.

Num contexto como o atual, com a difusão de muitas ferramentas sofisticadas de mapeamento, conhecer o terreno é condição essencial para uma ação bem sucedida de um número cada vez maior de atores. Mais do que isso, conhecer as geografias do território em questão é, sem dúvida, aspecto fundamental para a ação. Nestes termos, as teorias que se desenvolvem para explicar a atual organização espacial do mundo contemporâneo, procuram mapear, ainda que mentalmente, ou descritivamente, fixos e fluxos. Conhecer o mundo, entendê-lo e explicá-lo, passa pela condição da apropriação da noção de espaço, muitas vezes passando pelo uso, ainda que mínimo, de documentos cartográficos e dos softwares de mapeamento. Para Martinelli:

....a finalidade mais marcante em toda a história dos mapas, desde o seu início, parece ter sido aquela de estar sempre voltada à prática, principalmente a serviço da dominação, do poder. Sempre registrava o que mais interessava a uma minoria, fato este que acabou estimulando o incessante aperfeiçoamento dele.

A apreensão do espaço e a elaboração de estruturas abstratas [leia-se mapas] para representá-lo sempre marcaram a vida em sociedade dos homens. (MARTINELLI, 2006, p.8) 
Bem se sabe que, atualmente, muito tem sido escrito sobre o "desaparecimento" dos territórios, das fronteiras e dos lugares. No entanto, ao lançar um olhar mais detido sobre as teorias veremos que elas passam pela apropriação de noções espaciais. No entanto, a compreensão limitada do espaço, induz á leituras limitantes da realidade. Ainda que aquela discussão esteja posta hoje de maneira muito forte, o espaço está na ordem do dia, como aponta Haesbaert (2006).

Roger Brunet destaca, dentre outros elementos fundamentais do mundo contemporâneo, a força e a importância da dimensão espacial, frente ao avanço da globalização que parece suprimila. Afirma o geógrafo que as coletividades territoriais (regiões, estados, cidades, etc), aumentam sua importância no ordenamento territorial e no urbanismo, na recomposição dos territórios, contribuindo, assim, segundo ele, para diferenciá-los (BRUNET, 2007a).

Para a geografia a compreensão do espaço passa pelo uso do mapa, forma consagrada de expressão espacial na ciência geográfica (SANTOS, 2002). Em uma de suas obras Harvey (1983, p. 371) buscou mostrar o que considerava como "grande estima dos geógrafos pelo mapa", como meio de descrição e análise da informação geográfica. Martinelli (2006, p. 7) chega a afirmar em seu livro que "a geografia sempre foi confundida com o mapa". Complementa afirmando que ante o final do século XIX, "fazer geografia era fazer mapas". Aliás, ainda hoje esta é a razão pela qual muitos geógrafos se tornaram geógrafos, como menciona Massey (2008, p. 159).

A leitura do mundo, para o geógrafo, passa pelo entendimento do espaço e dos seus territórios, e essa compreensão vem em larga medida através do uso dos mapas, ainda que Girardi (2000) e Martinelli (2006) apontem que os mapas nos trabalhos da geografia, muitas vezes são usados apenas como "mapa-ilustração" e não como meio de leitura territorial. Talvez isso evidencie algo que há no imaginário dos geógrafos de que o discurso geográfico, para ter validade, precisa fazer uso de mapas. Mas, às vezes, ele não é usado de maneira adequada. Para nós, geógrafos, parece claro que entender o mundo através da sua dimensão espacial e afirmar a cartografia como meio legitimo de fazer isso é fundamental.

Durante muito tempo imperou na Geografia Crítica, talvez profundamente influenciada pelo pensamento de Yves Lacoste (1988) em sua obra seminal "A geografia: isso serve, em primeiro lugar, para fazer a guerra", de que a cartografia e, por conseguinte, os mapas, eram instrumentos da dominação capitalista. A Geografia Crítica, por sua vez, promove um relativo esquecimento do pensar a cartografia (GIRARDI, 2000, p. 42). Ler de forma crítica a sociedade parecia ter como requisito deixar de lado essa "ferramenta de dominação". Ao mesmo tempo, a geografia quantitativa passa por um período fecundo de produção de modelos cartográficos (no seu sentido quantitativo), sendo duramente criticada pela Geografia Crítica, como se poderia esperar. Os modelos e as representações cartográficas eram, assim, acusados como "aliados do diabo capitalista" para tomar as palavras de Brunet (2007c).

As duas correntes contribuíram, é verdade, de modo significativo para o desenvolvimento da geografia enquanto conhecimento científico, cada uma com seus méritos e fragilidades. Sabe-se hoje que nenhum conhecimento científico é neutro, e isso não se aplica somente à Geografia. Ele pode servir para diferentes finalidades. Pode servir para a construção de um discurso emancipatório, assim como para a estigmatização, tanto para a liberdade quanto para a dominação. O conhecimento do qual se origina a técnica e a tecnologia abre imensas possibilidades entre a dominação e a liberdade. A questão que se coloca é a de como o conhecimento é posto à disposição das diferentes classes sociais e setores da sociedade. Certamente, a concordância é ampla quanto a afirmação de que o acesso à tecnologia e à informação é extremamente desigual numa sociedade capitalista, como inúmeras vezes já apontou o geógrafo Milton Santos (2008).

Nesses termos, é preciso, então, construir um discurso politicamente comprometido com as classes sociais mais desfavorecidas e não ficar ao largo dos avanços tecnológicos que servem para a dominação e oprimem a liberdade e a democracia de fato, muitas vezes em função da insistente

Mercator - volume 8, número 17, 2009: set./dez. 
rejeição dos cientistas sociais em se apropriar dos avanços técnicos em favor da sociedade. Não se trata, portanto, de deixar de lado a técnica e tecnologia, pois compreendemos que são ferramentas essenciais para a promoção da emancipação, assim como é para a dominação. A pergunta a se colocar é: qual uso estamos fazendo dela? Por assim dizer, ciência, tecnologia e informação andam lado a lado com o poder.

Entendemos que uma leitura crítica da sociedade, nos moldes que a Geografia Crítica apontava, pode e deve ser feita com a apropriação das técnicas e das tecnologias. Algo semelhante foi esboçado por Girardi (2007) ao elaborar o "Atlas da questão agrária brasileira" no qual propõe uma cartografia geográfica crítica, fazendo uso, inclusive, da teoria da modelização gráfica desenvolvida por Roger Brunet, aliás, intensamente criticado por Yves Lacoste. Sua crítica ficou muito evidente em um número da revista de geografia e geopolítica Hérodote de 1995 (número 76) que possui como título "Les geographers, la science et l'illusion: chorématique stop". Lacoste, ainda, em seu "Dictionaire de la geographie: de la géopolitique aux paysages", afirma que a coremática é hoje o principal objeto de polêmica entre os geógrafos. Mesmo com a existência de tanta discórdia entre a coremática (que se trataria de uma abordagem meta-cartográfica) e os geógrafos críticos, Girardi consegue fazer uma abordagem crítica da realidade da questão agrária brasileira. Reforçamos aqui o que já dissemos, importam sim, os usos que se fazem da ciência e da técnica. O que é primordial não é a técnica em si, mas sim os usos que se fazem dela.

Num mundo que tem se tornado tão complexo, torna-se maior a exigência da aplicação de conceitos geográficos complexos, difícil de serem explicitados por uma cartografia que tanto prioriza a precisão e o detalhe. Câmara, Monteiro e Medeiros (2001) analisando as possibilidades de aplicação computacional aos conceitos elaborados por Milton Santos, registram a impossibilidade técnica de sua operacionalização, pelo menos até hoje. É o caso, por exemplo, dos conceitos de "sistemas de objetos" e "sistemas de ações" presentes na obra "A natureza do espaço" (2008), os quais remetem à idéia de que o espaço não é somente as formas e os objetos geográficos, mas a vida que os anima.

A limitação da maioria dos SIGs (Sistemas de Informações Geográficas) em expressar graficamente uma ampla gama de processos e conceitos próprios da Geografia Crítica implica pensar em outras formas de representação do espaço e das questões sociais, que são complexas e dinâmicas por definição. A teoria dos coremas pode ser uma via a se desenvolver neste sentido.

Assim, falar hoje das questões sociais exige pensar o espaço e em como representá-lo. Face à complexidade que se instala sobre os territórios, importa-nos depreendermos das perspectivas geométricas e olhar para esses mesmos territórios sobre uma perspectiva existencialista, como propõe Silveira (2006). Os limites dos fenômenos geográficos podem hoje se tornar imprecisos, mas o espaço a que eles se vinculam ainda é elemento fundamental. Ao contrário dos cartógrafos, para o geógrafo o objetivo principal não é medir o mundo, mas sim compreendê-lo. Por essas, dentre outras razões, uma outra cartografia, como forma de representar o mundo e suas mutações é fundamental. A teoria dos coremas, como meio de representação espacial, é hoje a que mais se aproxima dessas preocupações que agora estamos colocando.

\section{A COREMÁTICA}

Minha aproximação da teoria dos coremas ocorreu no final da pesquisa de iniciação científica, ainda na graduação. Tal interesse se deu em função dos resultados gráficos do mapeamento realizado em Presidente Prudente que resultou em um mapa síntese. O resultado final, ou seja, o mapa síntese, se revelou um mapa para ler e não um mapa para ver, nos termos estabelecidos por Jacques Bertin (1988). Entretanto, em função da quantidade de caracteres e informações contidas no mapa, ele se revelou de difícil leitura. Para Bertin $(1986,1988,1999)$ muita informação gráfica numa representação constitui uma barreira para a visualização, uma barreira de natureza psicológica em função da dificuldade encontrada pelo cérebro em processar grande quantidade de informação 
visual. Face á essas limitações optamos por trabalhar com uma abordagem coremática dos processos sociais intra-urbanos, através da qual poderíamos avançar no aspecto da representação gráfica, já que ao considerar o essencial para entender o território, elimina as contingências, ou seja, aquilo que tem importância secundária, facilitando a percepção visual. Sendo assim, a teoria dos coremas também está atrelada aos princípios da semiologia gráfica, se traduzindo em maior eficácia visual.

Importa nesse momento discorrer sobre alguns aspectos históricos e conceituais da teoria dos coremas. Vale ressaltar que ela também é chamada de teoria da modelização gráfica ou coremática. Portanto, em diferentes momentos poderemos estar usando essas diferentes terminologias, mas que tem sentido análogo, ou seja, trata-se do mesmo método.

O uso de modelos gráficos na geografia não é novidade. Menos ainda entre outras ciências. Em uma palestra proferida para a Societé de Geographie de Liège Roger Brunet (2007c) afirma que a ciência para avançar no entendimento do mundo faz freqüentemente uso de modelos, sejam eles gráficos ou não. O autor menciona que a palavra modelo vem do francês "moule" e tem ligação com a palavra "méd". O primeiro termo evoca a idéia de uma figura que serve para reproduzir, enquanto que o segundo é tido como medida, a partir dos quais deduz que se trataria de "tomar medida de", trazendo a noção de avaliação e ajustamento. Em termos mais claros, poderíamos entendê-los aqui como figuras usadas como referência para entender algo.

De acordo com Brunet, para se entender muitas coisas é preciso usar modelos, pois sempre entendemos algo por comparação ao que já é conhecido. Aliás, toda ciência faz uso de modelos. O que é uma definição senão um modelo. Nestes termos, toda a definição de um objeto propõe/ pressupõe um modelo. Brunet chama a atenção para os estudos geomorfológicos e dá o exemplo da definição de cuesta. A definição, pensada enquanto modelo para entender uma questão real, permite identificar no terreno configurações geomorfológicas que ela pressupõe. No entanto, ao confrontar cuestas no terreno, será possível verificar que elas nunca são idênticas. Mesmo assim o modelo permite explicá-las, em especial os processos que a originam e que nela ocorrem. Assim como o exemplo da cuesta, poderíamos tomar exemplos de outras áreas da ciência que encontraríamos a mesma questão.

Uma definição clássica de modelo, segundo Brunet (2007c) e Ferras (1993) foi dada por Haggett em 1965, utilizada por muitos geógrafos quando queriam falar sobre modelos. Haggett afirma que um modelo "é uma representação idealizada do mundo real, construída para demonstrar algumas das suas propriedades". De acordo com Brunet (2007c) uma outra definição foi dada por Alan Ray, para o qual um modelo "é um sistema representante de estruturas essenciais de uma realidade". No entanto, Brunet lembra que essas definições eram sempre evocadas com a idéia de simplificação tomada para demonstração e, para ele, isso representa um grave deslize.

\section{a) Os modelos na literatura científica}

Como lembra Brunet a geografia não é a única, nem mesmo a pioneira no uso dos modelos, pois outros ramos da ciência e outros meios já têm mais tradição no seu uso. Ferras (1993) afirma que podemos encontrar modelos na arquitetura e no urbanismo, na química, na física, na literatura, na etno-antropologia, assim como nas canções populares, nas artes e em caricaturas. Desde muito cedo, como aponta Théry (2004), os físicos lançaram mão dos modelos para representar os átomos. $\mathrm{Na}$ antiguidade, Demócrito e Epícuro imaginaram que os átomos eram pequenos objetos, dotados de ganchos que asseguravam a coerência da matéria. O tempo passou e os modelos correspondentes mudaram bastante. Quando o homem passa a observar o sistema solar, o átomo é concebido como uma versão em miniatura desse sistema. Atualmente os físicos pensam mais nas linhas da física quântica, na qual uma partícula pode estar em mais de um lugar ao mesmo tempo, o que impede de dar mais de uma probabilidade de localização do elétron (THÉRY, 2004). Do exemplo da física é possível extrair uma valiosa conclusão: nenhum modelo pode, nem deve ser permanente, pois na 
medida em que as ciências progridem os modelos também vão incorporando as mudanças. Isto é tanto mais verdade quando olhamos para o território, pois, para além de uma realidade física, há também uma realidade social que está em constante mudança. Assim, não importa somente o território como substrato, mas a vida que o anima e cria as formas, como já afirmaram Roger Brunet e Milton Santos. Assim, falar de modelos, em todos os ramos da ciência, é sempre falar de uma representação abstrata e provisória da realidade, mas ela é muito útil enquanto não é ultrapassada, segundo nos alerta Théry.

Na figura 1 é possível verificar a evolução dos modelos atômicos e suas representações gráficas.

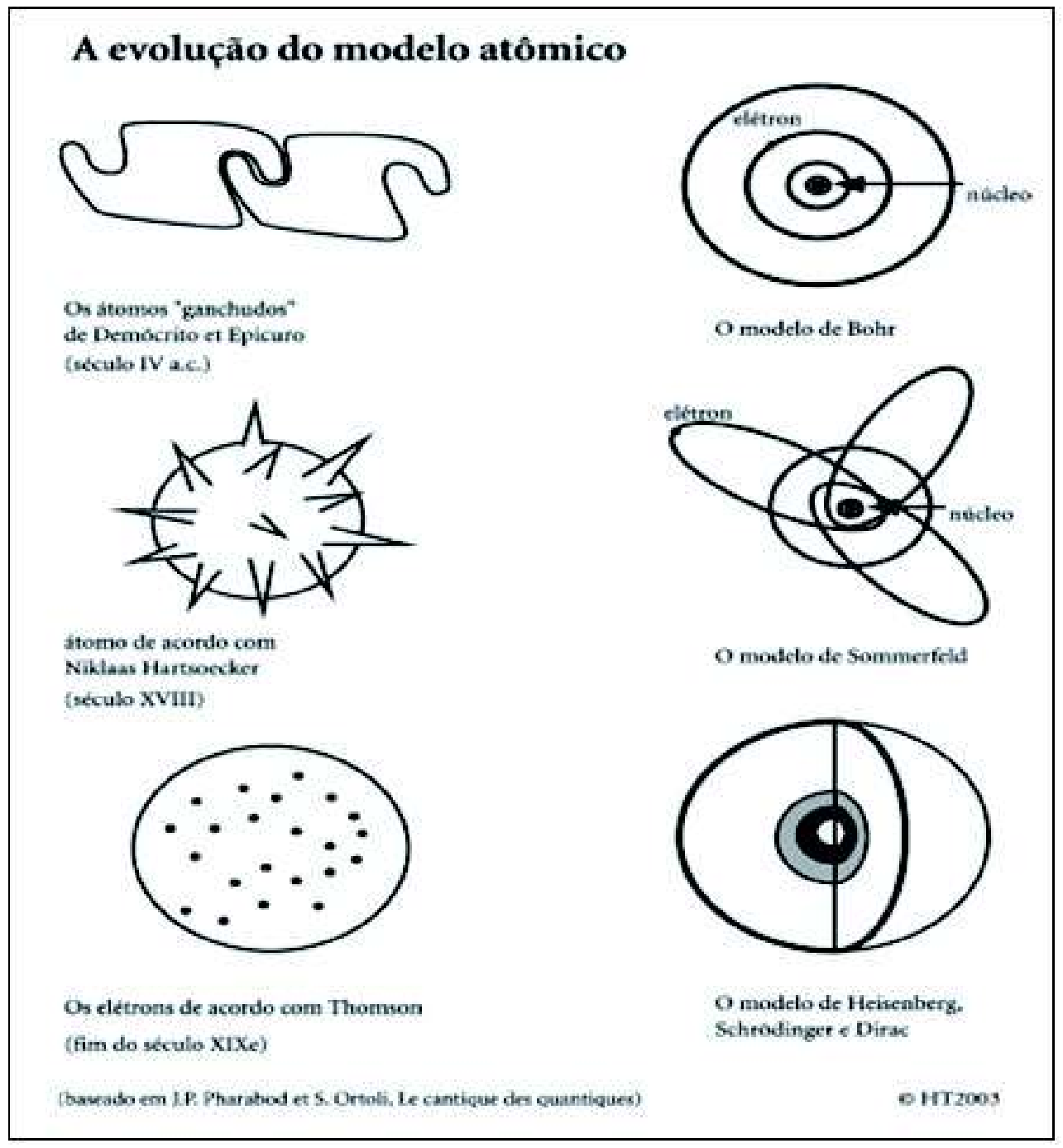

Figura 1 - Modelos da Física

Fonte: Théry, 2004.

Na História também podemos encontrar vários exemplos de modelos gráficos que ajudam a explicar fatos históricos que ultrapassam séculos, e até mesmo batalhas e guerras bastante complexas do ponto de vista dos elementos a serem considerados de modo descritivo. Exemplos disso são as representações gráficas de batalhas e as árvores genealógicas. Podem parecer simples, mas são extremamente eficientes em sua demonstração, resumindo momentos decisivos ou séculos de história, de uma dinastia ou de uma família real, tal como pode ser visualizado na figura 2. 


\section{Dois exemplos de uso dos modelos gráficos em História}

\section{A) Austerlitz}
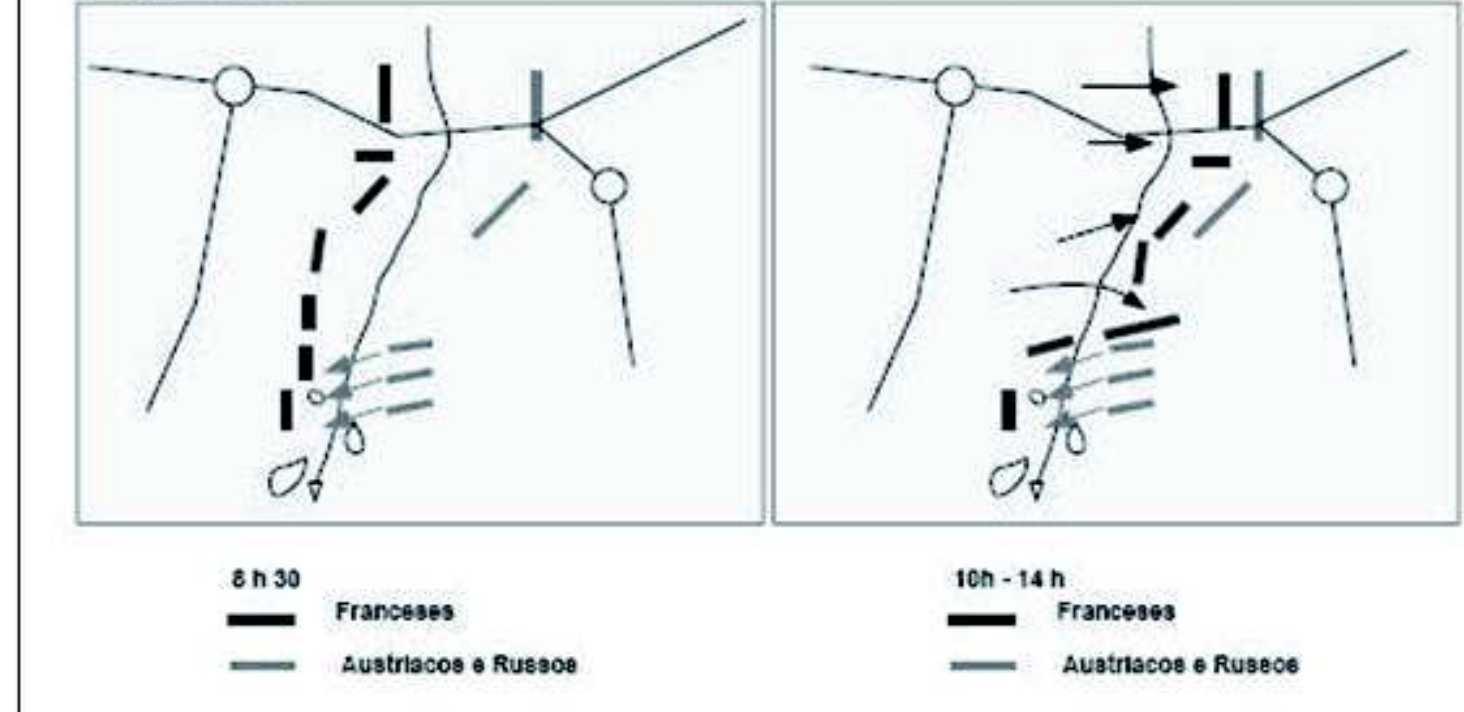

$10 \mathrm{ch}-14 \mathrm{~h}$

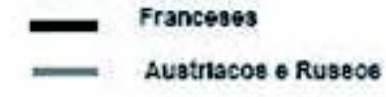

B) Uma árvore genealógica

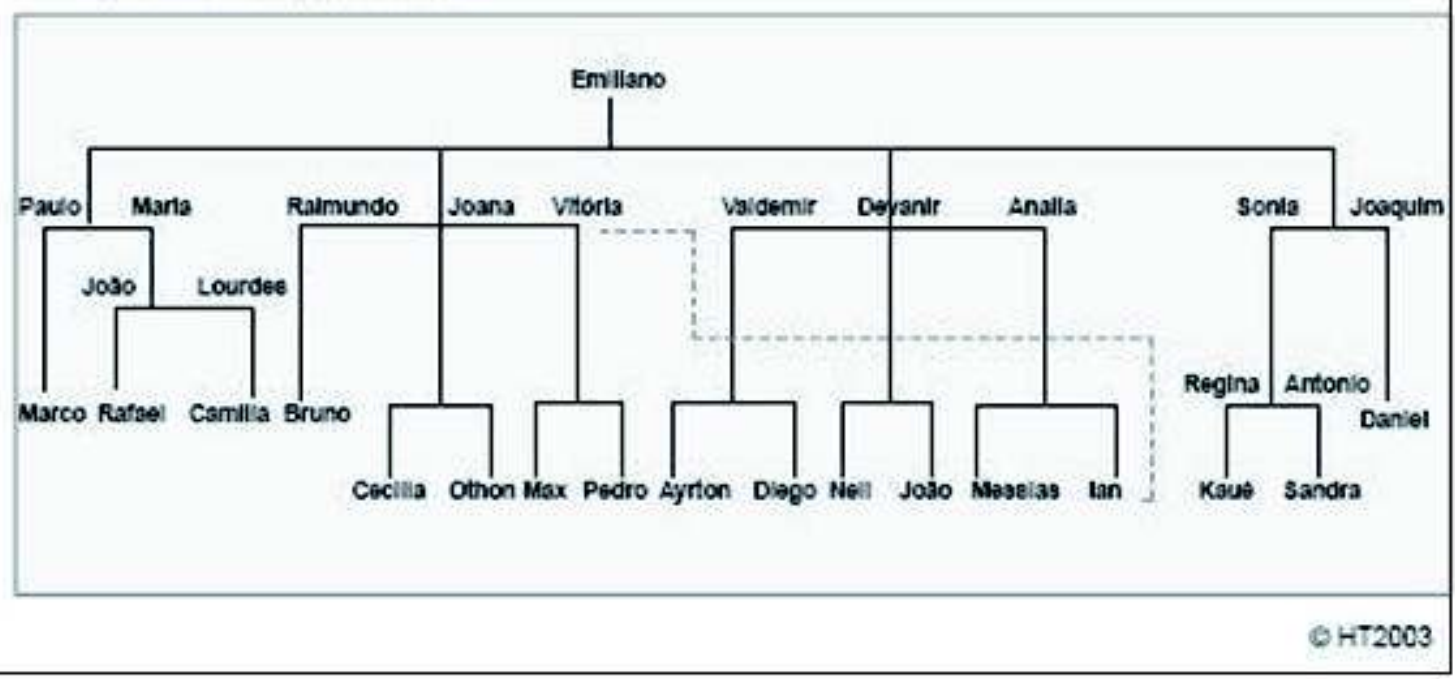

Fonte: Thery, 2005

Figura 2 - Modelos da história Fonte: Thery, 2005 


\section{b) Os modelos na geografia}

A Geografia, por sua vez, sempre fez uso de modelos, mas sem admiti-los. A geomorfologia é a que de longe mais faz uso de modelos gráficos para explicar a conformação dos terrenos e os processos neles engendrados. Para a geomorfologia, é uma necessidade que ajuda muito na compreensão dos fenômenos por ela estudados. Além da geomorfologia outros exemplos de modelos na Geografia também podem ser citados, como os modelos de Christaller. Esses exemplos estão expressos na figura 3.

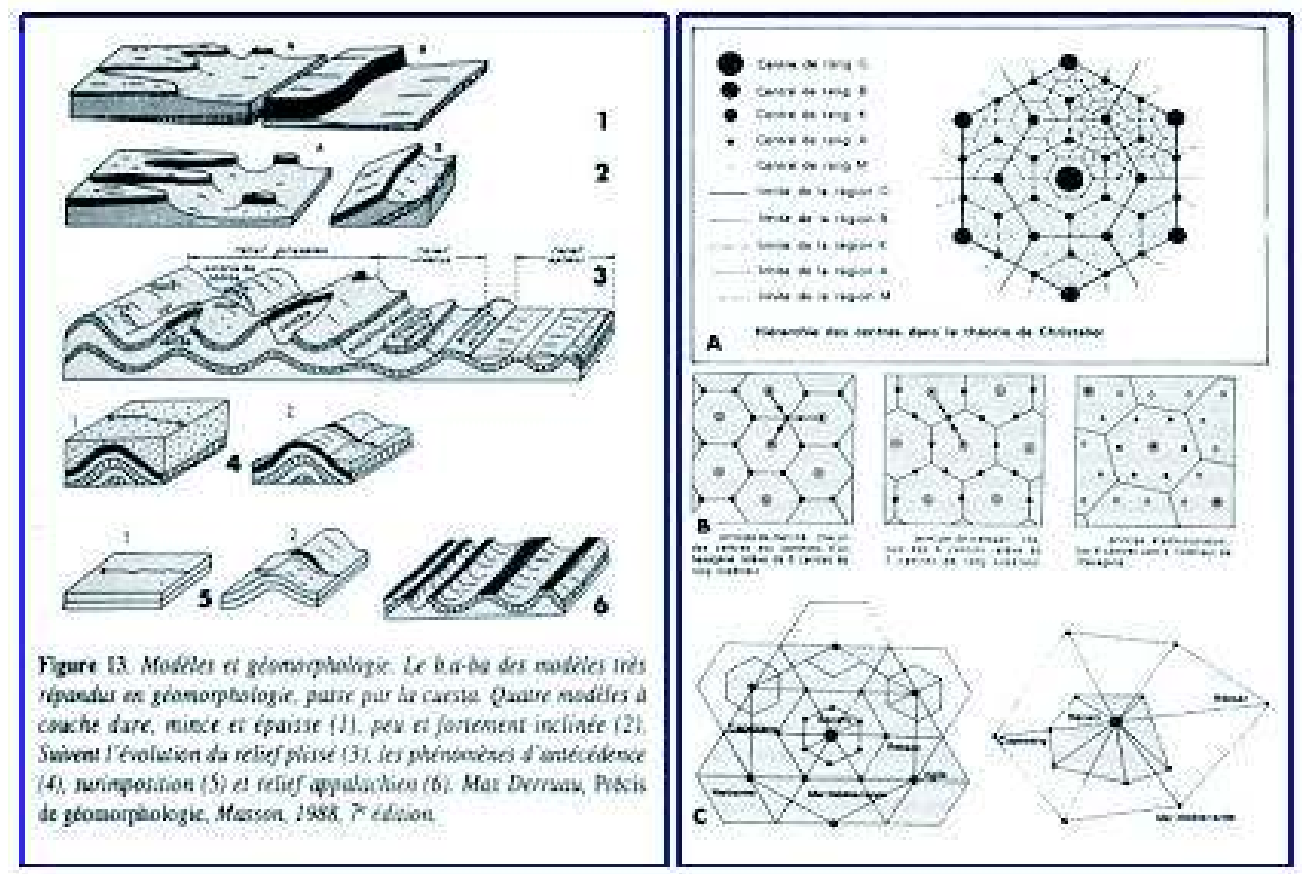

Figura 3 - Modelos clássicos da Geografia

Fonte: Cedida por Thery na disciplina “Análise prospectiva geográfica e ambiental dos territórios” em 2006, na Unesp, Presidente Prudente.

No entanto, Brunet nos afirma que é durante as décadas de 60 e 70, que os modelos têm uma entrada marcante na geografia, em especial sobre a égide da Geografia Quantitativa. "Nunca houve um período tão rico de produção de modelos" afirma Brunet (1999). Evidentemente que esta entrada não se deu sem críticas, uma vez que muitos denunciavam os modelos qualificando-os como aliados do capitalismo. Apesar de se produzir tantos modelos gráficos, acompanhados de normas e regulamentos no bojo da Geografia Quantitativa, não havia uma teoria sistematizada sobre o seu uso.

Somente na década de 1980 surgem as primeiras formulações teóricas sobre o uso dos modelos na Geografia com um artigo de Roger Brunet publicado no número 4 da revista francesa "L'espace geographique", denominado "La composition des modèles dans l'analyse spatiale" (BRUNET, 1980). A teoria foi desenvolvida e aplicada como instrumento de análise regional, até mesmo para subsidiar o ordenamento territorial, a partir de um grupo de geógrafos reunidos em torno dos trabalhos do GIP-RECLUS2 (Groupement d'intérêt public - Réseau d'études des changements des localisations et unités spatiales), liderado por Brunet. Vários outros trabalhos se sucederam após o artigo de 1980 (BRUNET, 1986, 1987), de modo que a teoria foi amplamente desenvolvida em uma obra mais recente chamada "Le dechiffrement du monde" (2001), onde explora de modo aprofundado a axiomática sobre a qual está baseada a teoria, que convencionou chamar de teoria 
dos coremas, teoria da modelização ou coremática.

Dosse (1994) afirma que essa teoria está assentada sobre o estruturalismo e aponta, por conseguinte, que em função da entrada tardia da Geografia na discussão estruturalista, os possíveis desdobramentos nessa área estão longe de terminarem, mostrando-se como um terreno ainda muito fecundo (isto revela tanto uma incompletude quanto a necessidade de mais estudos). Dosse trata a coremática como um ponto culminante de ligação entre a ciência ideográfica (espaços sociais descritos) à sua vertente nomotética (produzir os princípios gerais da organização dos espaços da sociedade). Aponta ainda que ela está muito ligada à linguagem estruturalista, estando os coremas como uma linguagem gráfica para geografia, em torno de estruturas espaciais elementares, assim como a noção de fonema, que trata das unidades mínimas da linguagem, está para a lingüistica.

Muitos acusaram e acusam o modelo de tratar apenas de simplificação, questão sobre a qual Brunet se debruça em suas obras, afirmando que não é o caso. Trata-se de identificar as formas que a sociedade produz ao trabalhar o espaço (BRUNET, 2007), e fazer aparecer as estruturas presentes no território. Para Thery (2004), trata-se aqui de indentificar estruturas, as fortes e as contingentes, ou seja, fazer ressaltar aquilo que é verdadeiramente representativa do espaço e aquilo que é apenas acessório. Por isso Brunet menciona que ser amante dos detalhes, como eram os geógrafos da Geografia Regional Clássica, é condenar a modelização. Por outro lado, é possível buscar a identidade de uma região indo do geral aos detalhes e vice-versa, sem condenar as possibilidades de comparação, como ocorria na Geografia Regional. O trabalho nomotético é favorecido em oposição à ideografia.

Ao identificar as estruturas essenciais de um território e representá-las graficamente abrem-se as possibilidades para o que Thery (2004) coloca como uma gramática do território. A combinação dessas diferentes estruturas, identificadas e representadas graficamente, nos forneceria um corema, um modelo. A combinação composta por cada modelo, para Brunet (2001) e Thery (2004), é única, de modo em que se pode falar em modelo do único, que é aquele que expressa a identidade do território considerado. Neste sentido, algumas estruturas estarão presentes em mais de um território, o que abre possibilidades de comparação entre diferentes realidades.

Um exemplo desse pode ser constatado ao comparar os modelos da Indonésia e do Brasil (figura 4), onde ainda existe o fenômeno das frentes pioneiras, presente hoje apenas em alguns países do mundo. Ao representar essa estrutura gráfica como representativa do território em questão poderemos perceber as similitudes.

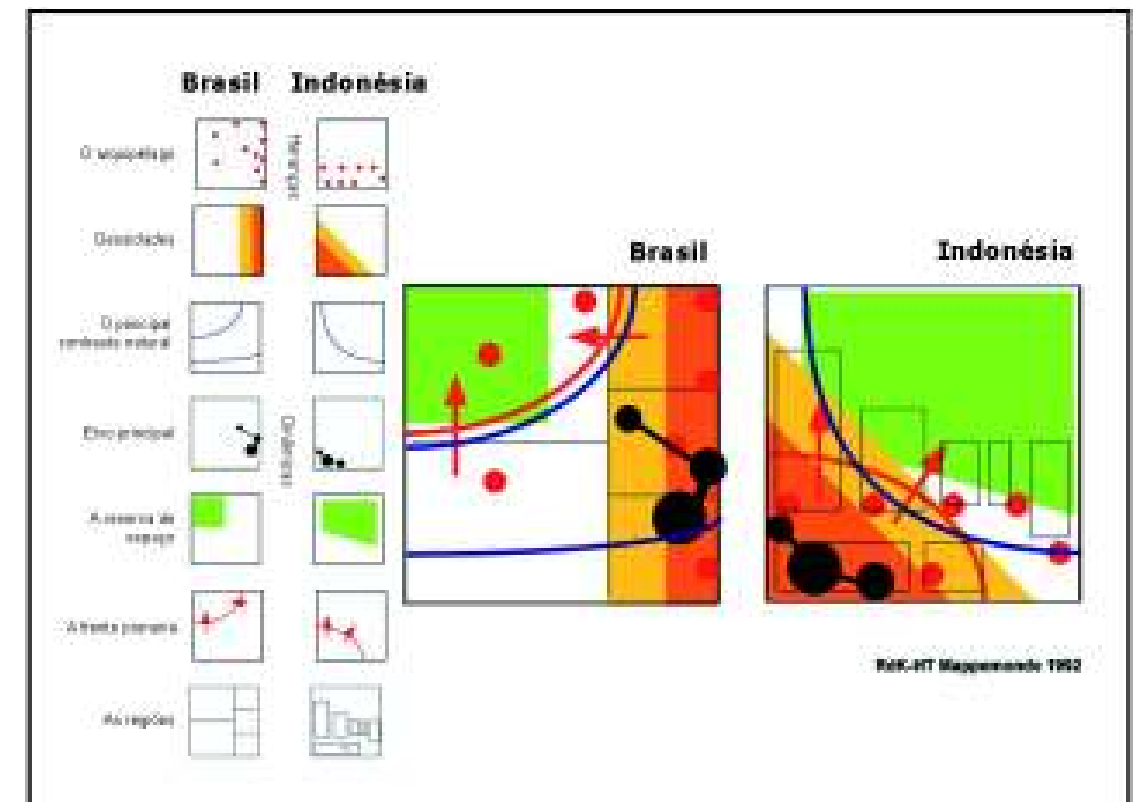

Figura 4 - Modelos do Brasil e da Indonésia

Fonte: Cedido por Hervé Théry na disciplina “Análise prospectiva geográfica e ambiental dos territórios” em 2006, na Unesp/Presidente Prudente.

Mercator - volume 8, número 17, 2009: set./dez. 
A partir da identificação de estruturas que se repetem em territórios diferentes, Brunet, propõe uma tabela denominada de tabela dos coremas (figura 5). Com esta tabela ele pretende que sua função para a Geografia seja a mesma que a Tabela de Mendeleiev tem para os químicos.

\section{Coremas propostos por R. Brunet}

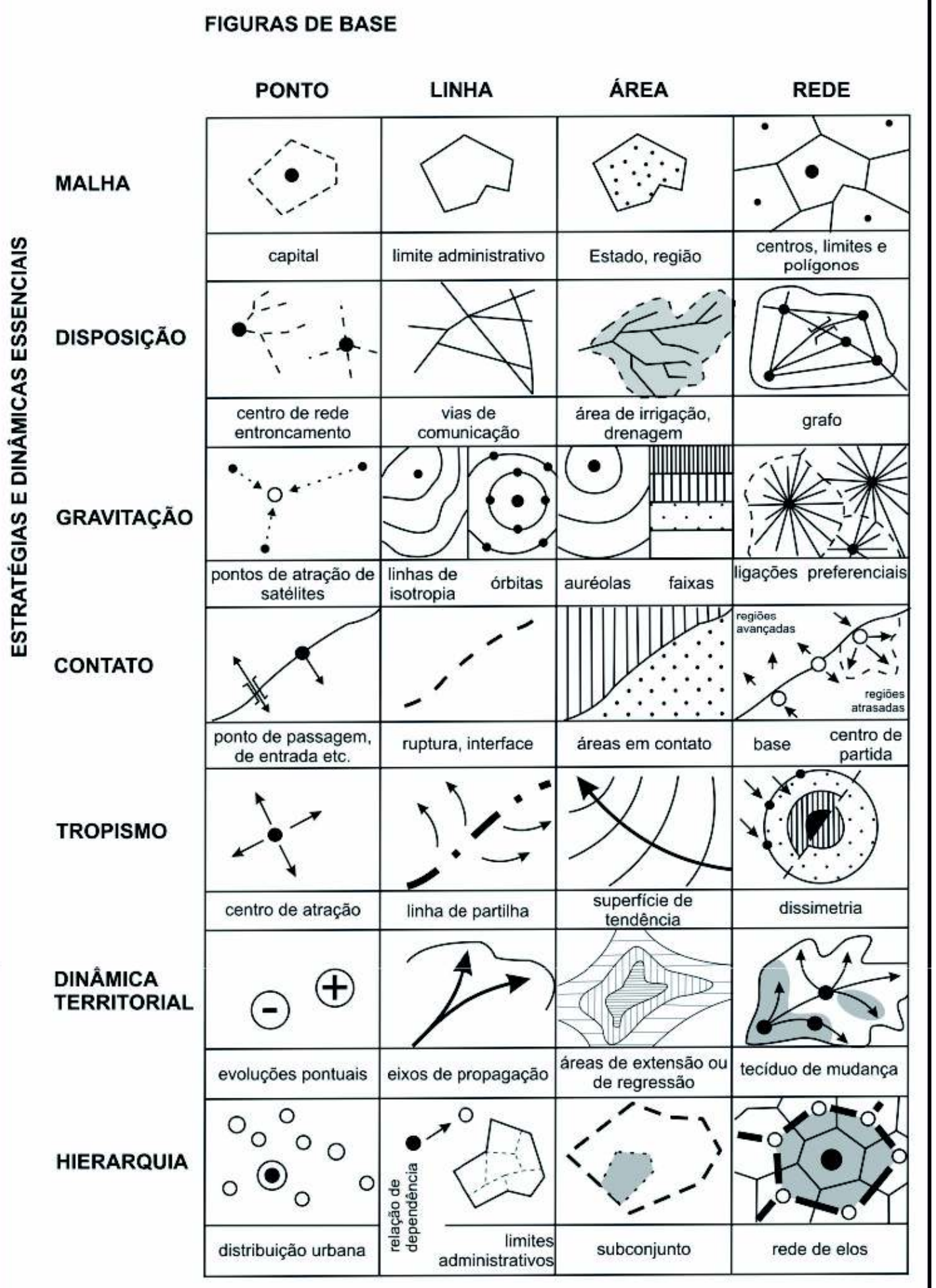

Figura 5 - Tabela dos coremas

Fonte: BRUNET, 2001

Estabelecida por Roger Brunet, resultado do cruzamento entre quatro figuras de base (em colunas) e sete dinâmicas (em linhas). 
Por meio da modelização gráfica é possível representar estruturas, dinâmicas e processos, que são difíceis de serem explicitadas através da cartografia tradicional. Para além disso, abrem-se as possibilidades de comparação entre diferentes realidades.

Vale lembrar que através da modelização podemos graficar conceitos e processos importantes na pesquisa geográfica. Além disso, o seu caráter didático é substancial. Por se valer das propriedades da semiologia gráfica, sua apreensão é bastante fácil. Robert Ferras, um dos animadores dos debates em torno da coremática, antes de iniciar os trabalhos propriamente acadêmicos sobre os modelos, atuou em escolas de ensino primário na França ensinando a modelização para os alunos (THERY, 2004; FERRAS, 1993). O seu sucesso entre as crianças vem atestar também seu caráter didático e pedagógico.

\section{c) Meios de divulgação da coremática}

Atualmente o principal meio de divulgação das idéias da modelização é a revista Mappemonde. Trata-se de uma revista francesa, criada no ano de 1986 por sugestão de Robert Ferras. Em 2004 ela passa a ser publicada inteiramente em formato digital na internet, ampliando o acesso à ela, $o$ que contribui à divulgação da coremática.

Nesta revista é possível encontrar exemplos de muitos modelos gráficos e teóricos aplicados para as mais diversas realidades e regiões do mundo. Nela se encontram ainda alguns procedimentos metodológicos para operacionalizar a modelização dos territórios representados. É o caso do trabalho de Patrick Poncet (2004), onde ele demonstra os passos para se geometrizar um território representado em bases tradicionais. Ele expõe o exemplo da base da Espanha, levada a uma forma geométrica por Robert Ferras e aplica com procedimentos próprios e mais elaborados para o caso da Austrália. Ainda que a principio este artigo, em particular, ajude a esclarecer alguns procedimentos da modelização, mais especificamente da geometrização dos contornos territoriais, Roger Brunet, em uma nota publicado em sua página pessoal na internet, alertou para os possíveis enganos que podem advir dessa prática, pois não se trata apenas de geometrizar o territorio representado, mas de comprender os processos essenciais que neles se dão e as formas produzidas pela sociedade (BRUNET, 2007 sobre PONCET, 2004 ).

Na revista, ainda é possível encontrar uma verdadeira cartografia dinâmica, como podemos verificar no artigo de Robert (2007). Com o auxílio de recursos computacionais e gráficos o site permite a exibição de mapas dotados de movimentos.

\section{d) Os modelos mais célebres}

Quanto aos modelos produzidos, temos vários exemplos. No momento vamos expor os mais significativos. Certamente, o mais famoso deles, elaborado por Roger Brunet é o modelo que ficou conhecido como "banane bleue" (figura 6) em toda a União Européia. O modelo teve uma grande divulgação na mídia. Ele foi publicado no Jornal "Le Nouvel Observateur" e logo denominada a dorsal européia (a megalópole européia, um eixo que se localiza entre Lancashire e a Toscane), e por assumir um formato semelhante a uma banana, e ter a cor azul em função da impressão monocromática, passou a ser chamada de banane bleue, e assim ficou conhecida (BRUNET, 2002).

As idéias relacionadas à modelização ganham expressão no Brasil principalmente com Hervé Théry. Ele publica no ano de 1986 "Brésil, un atlas chorématique", no qual realiza um exercício de modelização para o caso do território brasileiro, considerando assim suas principais estruturas espaciais e suas dinâmicas (Figura 7). Ele também é responsável pela criação da revista eletrônica franco-brasileira Confins, que também publica trabalhos que aplicam a coremática. 


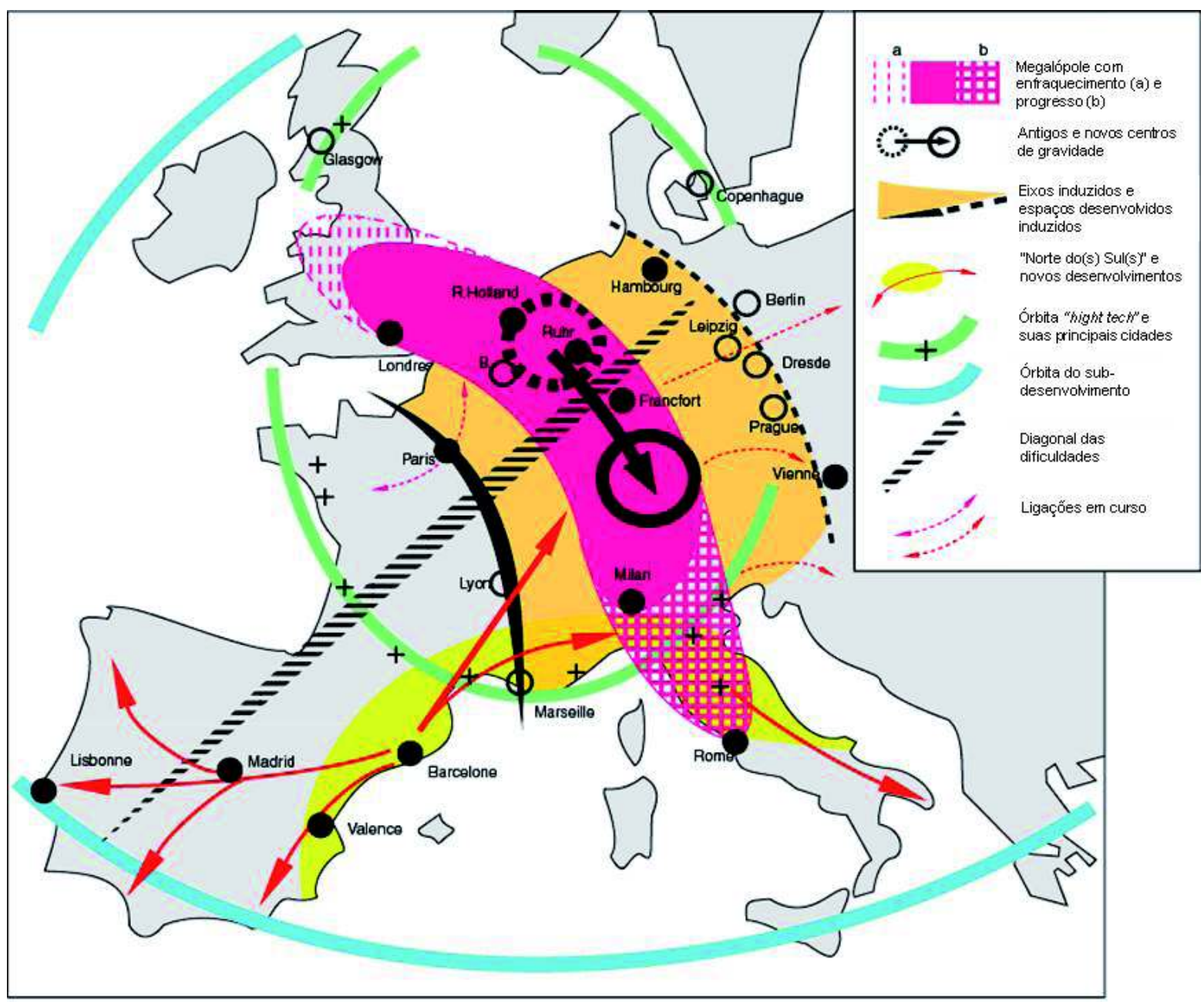

Figura 6 - Banane Bleue

Fonte: Cedido por Hervé Théry na disciplina “Análise prospectiva geográfica e ambiental dos territórios” em 2006, na Unesp/Presidente Prudente.

Na Unesp de Presidente Prudente já se nota sua influência, evidenciando que a coremática vem ganhando lugar em diversas pesquisas desta universidade. A partir da disciplina ministrada por Théry, foi feito um esforço de modelização para a 10a. Região Administrativa de Presidente Prudente. Tal abordagem também está presente no trabalho de Girardi (2006), "Atlas da Questão Agrária Brasileira" e de Martinuci (2008), "Circuitos e modelos da desigualdade intra-urbana". Poderíamos citar aqui vários outros trabalhos desenvolvidos pelos geógrafos já citados, como o modelo do território paulista (THERY, 2007), assim como o modelo do território francês feito pela equipe de Brunet. Mas no momento nos deteremos a esses exemplos para demonstrar as inúmeras possibilidades de aplicação do método, adequado para se trabalhar nas mais diferentes escalas, permitindo estudos mais analíticos e comparativos. 


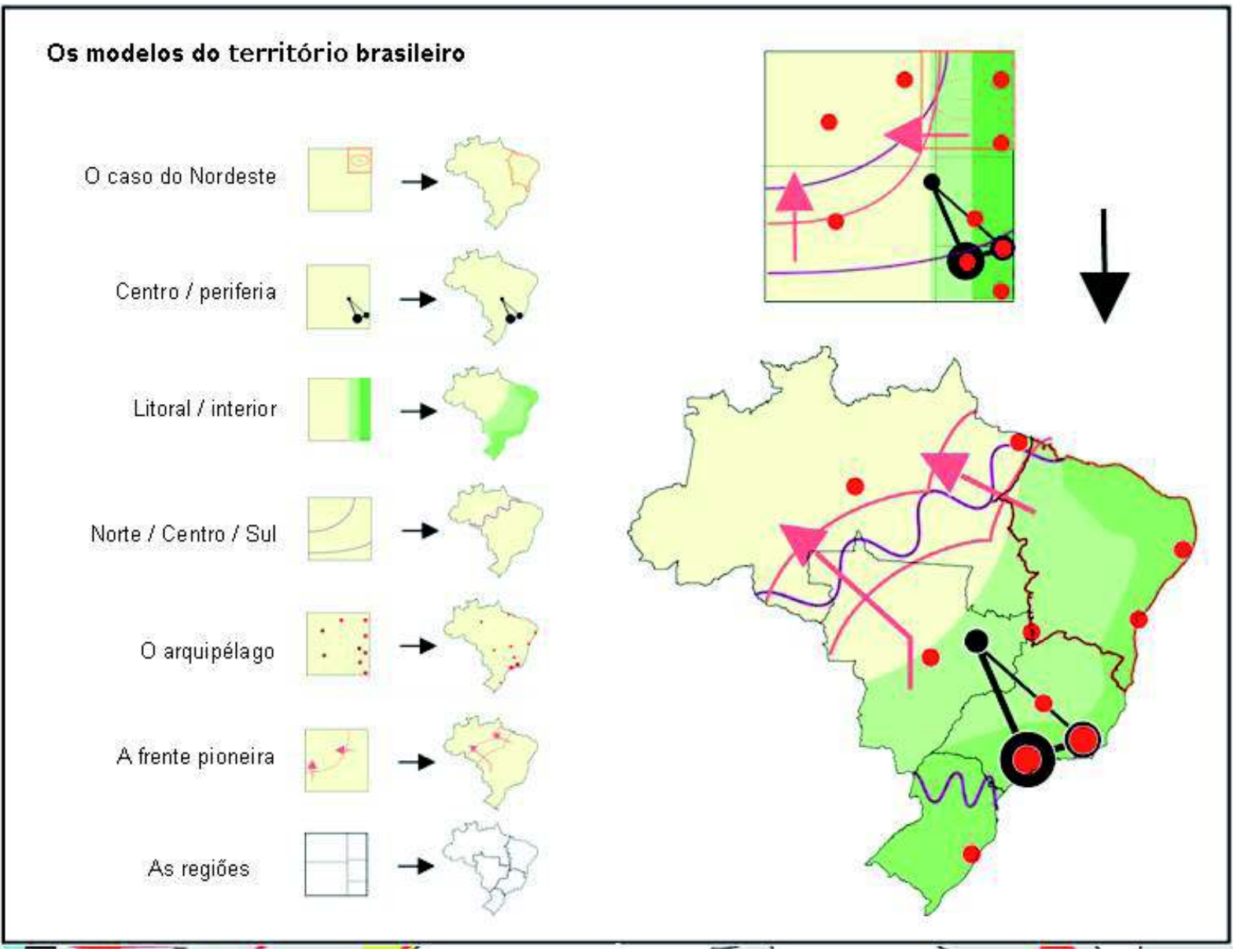

Figura 7 - Os modelos do território brasileiro Fonte: Cedido por Hervé Théry na disciplina “Análise prospectiva geográfica e ambiental dos territórios” em 2006, na Unesp/Presidente Prudente.

\section{CONSIDERAÇÕES FINAIS}

Os trabalhos de Brunet, Thery e Ferras afirmam que uma das vantagens de se trabalhar com a modelização gráfica é a possibilidade de realizá-la em diferentes escalas. Apesar disso, grande parte dos trabalhos parecem estar voltados para a análise regional, tradição entre os franceses. É preciso, por conseguinte, pensar na representaçao dos fenômenos espaciais em outras escalas, como por exemplo, na intra-urbana. Na cidade podem ser encontrados complexos processos de interação territoriais que por sua vez, poderiam ficar mais claros e evidentes com o uso do método coremático. Além do mais, face aos inúmeros estudos intra-urbanos que existem no âmbito da geografia, é preciso buscar formas de aproximação para a comparação das dinâmicas internas de uma cidade, possibilidade que é eliminada quando tratamos apenas das particularidade, sem dar a importância devida aos estudos comparativos. O método foi amplamente aplicado na França, ainda que aos estudos urbanos tenha sido dado menos importância, e seria muito salutar aplicá-lo amplamente ao caso brasileiro para experimentar suas possibilidades e enxergar os seus limites. Acredito que, se devidamente aplicado, pode trazer muitos granhos à geografia no que diz respeito não somente aos estudos comparativos, mas também no caráter pedagógico e semiológico das nossas representações. 


\section{NOTAS}

1. Agradeço a colaboraçao do Prof. Dr. Everaldo Santos Melazzo pela leitura da versão final do artigo, assim como pela suas sugestões. Também estendo meus agradecimentos a Igor Catalão que, gentilmente, fez a tradução do resumo para o francês e para o inglês.

2. Organismo de pesquisa científica na área de Geografia, que trabalhava em ligação com o Instituto Geográfico Nacional francês e com o INSEE, que na época tinha 27 membros. Muitos dos seus trabalhos tiveram um amplo apoio do Ministério da Pesquisa.

\section{REFERÊNCIA BIBLIOGRÁFICA}

BERTIN, J. A neográfica e o tratamento gráfico da informação. Curitiba : UFPR, 1986.

BERTIN, J. Ver ou ler : um novo olhar sobre a cartografia. Seleção de textos, AGB, São Paulo, v. 18, p. 45-62, 1988.

BERTIN, J. Semiologie graphique. 3. ed. Paris : EHESS, 1999.

BOARD, C. A contribuição do geógrafo para a avaliação de mapas como meio de comunicação de informações. GEOCARTOGRAFIA (textos selecionados de cartografia teórica). FFLCH (USP). USP: São Paulo, 1994.

BRUNET, R. La composition des modèles dans l'analyse spatiale. L'Espace géographique, n. 4, 1980, p. 253-265.

BRUNET, R. La cartes modèle e les corèmes. Mappemonde, n. 4, 1986, p.2-6.

BRUNET, R. . La carte, mode de emploi. Paris: Fayard/Reclus, 1987.

BRUNET, R. Le dechiffrement du monde. Paris: Belin, 2001.

BRUNET, R. Pour une pratique raisonée et rationelle de la représentation des territoires. Disponível em $<$ http://www.mgm.fr/ARECLUS/page_auteurs/Brunet4.html $>$ Acesso em fevereiro de 2007a.

BRUNET, R. Des modèles em géographie? Sens d'une recherche. Disponível em $<$ http://www.mgm.fr/ ARECLUS/page_auteurs/Brunet3.html. $>$. Acesso em fevereiro de 2007c.

CAMARA, G; MONTEIRO, A. M. V; MEDEIROS, J. S. de. Fundamentos Epistemológicos da ciência da informação. In: CAMARA, G; DAVIS, C; MONTEIRO, M. Introdução à ciência da geoinformação. São José dos Campos: INPE, 2001.

CASTRO, I. E. O problema da escala. In: CASTRO, I. E; GOMES, P. C. da C; CORREA, R. L. Geografia: conceitos e temas. 10 ed. Rio de Janeiro: Bertrand Brasil, 2007, p. 117-140.

DOSSE, F. A história do estruturalismo. v. 2. Campinas: Unicamp, 1994.

FERRAS, R. Les modeles graphiques na géographie. Paris/Montpelier: Economica/GIP Reclus, 1993.

GIRARDI, G. Leitura de mitos em mapas. In: Geografares. Vitória, n. 1, v. 1, p. 41-50, jun. 2000.

GIRARDI, E. P. Atlas da questão agrária brasileira. Qualificação (Doutorado em Geografia). Faculdade de Ciências e Tecnologia, Universidade Estadual Paulista, Presidente Prudente, 2007.

HAESBAERT, R. O mito da desterritorialização. 5. ed. Rio de Janeiro: Bertrand Brasil, 2008.

HARVEY, D. Teorias, leyes y modelos em geografia. Madrid: Aliança Editorial, 1983.

HÉRODOTE: Les geographes, la science et l'illusion. Paris, v. 97, n. 76, jan/mar. 1995.

JOLY, F. A cartografia. 10. ed. Campinas: Papirus, 2007.

KANAKUBO, T. O desenvolvimento da cartografia teórica contemporânea. GEOCARTOGRAFIA (textos selecionados de cartografia teórica). FFLCH (USP). USP: São Paulo, 1995.

KOEMAN, C. O princípio da comunicação na cartografia. GEOCARTOGRAFIA (textos selecionados de cartografia teórica). FFLCH (USP). USP: São Paulo, 1995.

KOLACNY, A. Informação cartográfica: conceitos e termos fundamentais na cartografia moderna. GEOCARTOGRAFIA (textos selecionados de cartografia teórica). FFLCH (USP). USP: São Paulo, 1992. 
LACOSTE, Y. A geografia: isso serve, em primeiro lugar, para fazer a guerra. Campinas: Papirus, 1988.

LACOSTE, Y. Les geographes, la science et l'illusion. In: Herodote: Paris, v. 97, n. 76, jan/mar. 1995.

LACOSTE, Y. Dictionaire de geographie. Armand Colin: Paris, 2003.

LOCH, R. E. N. Cartografia: representação, comunicação e visualização dos dados espaciais. Florianópolis: UFSC, 2006.

MARTINELLI, M. Mapas da geografia e cartografia temática. 3. ed. São Paulo: Contexto, 2006.

MASSEY, D. Pelo espaço: uma nova política da espacialidade. Rio de Janeiro: Bertran Brasil, 2008.

PONCET, P. Quel fond de carte pour l'Australie?. Mappemonde, n. 74, v. 2, 2004. Disponível em < http:// mappemonde.mgm.fr/num2/articles/art04206.html >. Acesso em novembro de 2006.

ROBERT, S. Le paysage visible de la Promenade des Anglais à Nice: essai d'une représentation cartographique dinamique. Mappemonde. Disponível em <http://mappemonde.mgm.fr/num14/articles/art07201. html> Acesso em abril de 2007.

ROSA, F. S. Impactos da Informática na Cartografia. In: Simpósio Intencional sobre Novas Tecnologias Digitais em Geografia e Cartografia, 1996, São Paulo. Anais... LEMADI, São Paulo, 1996.

SANTOS, D. A reinvenção do espaço. São Paulo: Editora UNESP, 2002.

SANTOS, M. Por uma outra globalização. 15. ed. São Paulo: Record, 2008.

SILVEIRA, M. L. O espaço geográfico: da perspectiva geométrica à perspectiva existencial. GEOUSP. São Paulo: USP, n. 19, 2006, p. 81-91.

THERY, H. Brésil: un atlas chorématique. Paris: Fayard/Reclus, 1986.

THERY, H. Modelização gráfica para a análise regional: um método. Geousp. São Paulo, n. 15, p. 179-188, 2004

THERY, H.A dimensão temporal da modelização gráfica. Geousp. São Paulo, n. 17, p. 171-183, 2005.

THERY, H. Sciences sociales e identité de la geographie. Disponível em < http://www.atmos.ggf.br/ novosite/index.php?option $=$ com_content\&task $=$ view\&id=37\&Itemid=26 $>$ Acesso em fevereiro de 2007.

THERY, H. Chaves para a leitura do território paulista. Disponível em $<\mathrm{http}$ ://www.seade.gov.br/produtos/atlasecon/> Acesso em maio de 2007.

THERY, H. Atlas do Brasil. 2. ed. São Paulo, EDUSP, 2008.

Trabalho enviado em outubro de 2009

Trabalho aceito em dezembro de 2009

Mercator - volume 8, número 17, 2009: set./dez. 